\title{
Smart Door Monitoring and Locking System using SIM900 GSM Shield and Arduino UNO
}

\author{
Sialee Leekongxue \\ School of Electronic Engineering \\ Tianjin University of Technology \\ and Education, Tianjin, China
}

\author{
$\mathrm{Li} \mathrm{Li}$ \\ Tianjin University of Technology \\ and Education, \\ Tianjin, China
}

\author{
Tomas Page \\ Beijing International Education \\ Institute \\ Beijing, China
}

\begin{abstract}
The problem with the safety of people's belongings at home is among some of the most important security problems to solve. One way of knowing that a house is safe is the door because when the door is locked, the house is safe. Hence, an attempt has been made here to develop a smart door that monitors the door state, sends an SMS to the owner when someone opens the door without unlocking it, the door can be locked and unlocked by sending an SMS from a mobile phone. One more feature is a lamp that can be switched on and off and will switch on when the door is unlocked and switch off when the door is locked. This system comprises an Arduino UNO, GSM Technology and other electronics components. The system has been successfully developed, implemented and tested in the laboratory and the result shows that it works as intended. This system is suitable for all kinds of houses and has been designed to be very economical so that it can be afforded by all.
\end{abstract}

Keywords-Arduino Uno; SIM900 GSM; Smart Door; SMS Notification.

\section{INTRODUCTION}

People use different kinds of security devices to provide protection to their life and assets. Ensuring safety and security of people and their valuables in the home is most important for avoiding illegal intrusion and theft [1]. Most people use key locks for the door of their homes, their lockers, cabinets, and other things. However, key locks can be easily broken and compromised by determined thieves and intruders. Therefore, as means of addressing this problem is to allow the people know the lock state such as the lock is locked, unlocked, the door is opened and closed using a smart door monitoring and locking system. This system will save all the states of the lock, the door and the lamp in the house. The owner can check the states by sending an SMS from a mobile phone and it will send an SMS to the owner when someone goes into the house without unlocking the lock or break the look. This system can also send an SMS to lock and unlock the door and switch the lamp on and off.

\section{LITERATURE SURVEY ON EARLIER WORKS}

The related works that use GSM technology and Arduino UNO are presented as the work describes the development of GSM based advanced alert home locker safety security system using the Arduino and SIM900 [2]. Back locker security system using RFID and GSM technology [3]. Advanced locker security system based on RFID, password and GSM technology with automatic movement of lock system [4]. Implemented a home security system with a GSM module with a microcontroller [5]. The locker opening and closing system with RFID, Fingerprint, Password, and GSM [6]. Smart home automation and security system using Arduino and IOT [7]. The web site Ran Dom Nerd Tutorials has made the project about control a $12 \mathrm{~V}$ lamp via SMS with Arduino [8].

\section{DEVELOPMENT}

This project's software development is based on the $\mathrm{C}++$ programing language using the Arduino IDE and installing it on an Arduino UNO board. The Block Diagram of the Smart Door Monitoring and Locking System is shown in figure 1 and the schematic diagram is in figure 2. This System consists of the main following units. There are:

- Arduino UNO

- SIM900 GSM shield

- Servo Motor

- Relay and Lamp

- Door Sensor

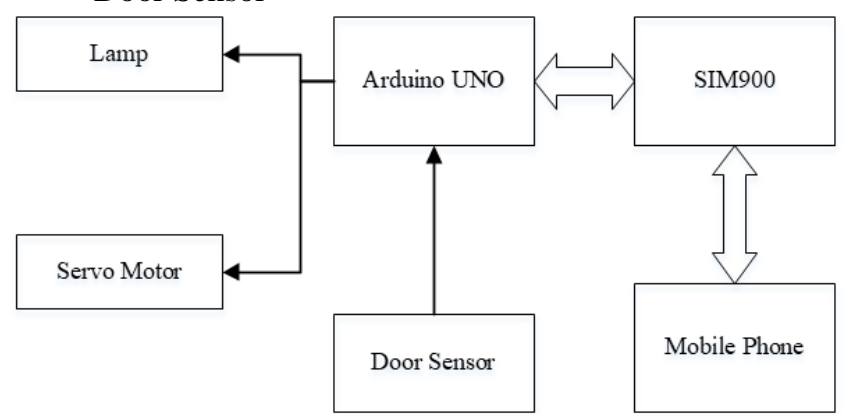

Figure. 1. Block diagram of the Smart Door Monitoring and Locking System.

\section{A. Arduino UNO}

The Arduino Uno is a microcontroller breakout board based on the ATmega328P (datasheet). It has 14 digital input/output pins, 6 analog inputs, a $16 \mathrm{MHz}$ quartz crystal, a USB connection, a power jack, an ICSP header and a reset button. It contains everything needed to support the microcontroller, simply connect it to a computer with a USB cable or power it with an AC-to-DC adapter or battery to get started [9]. 


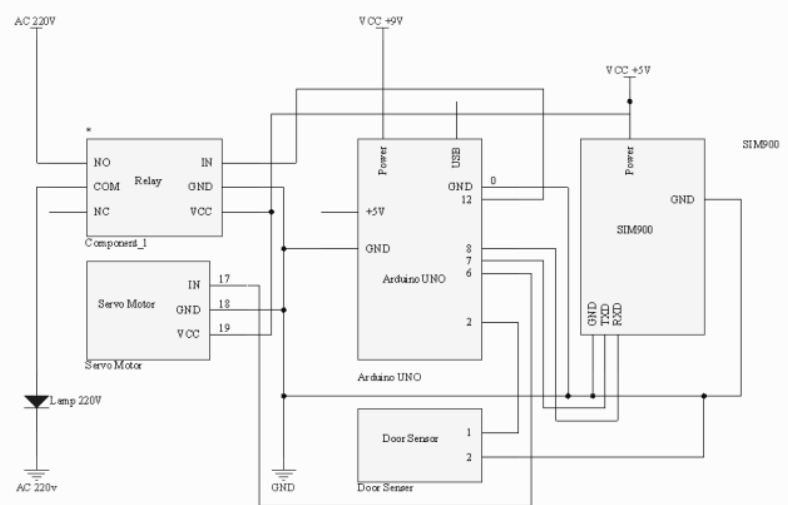

Figure 2. Schematic diagram of the Smart Door Monitoring and Locking System.

Arduino is an open-source platform and consists of both a physical programmable circuit. It has the IDE (Integrated Development Environment) that runs on a computer, used to write and upload computer code to the physical board. below.

The board is shown in figure 3 and the features are shown

- Operating Voltage: 5V

- Digital I/O Pins: 14 (of which 6 provide PWM output)

- Analog Input Pins: 6

- DC Current for 3.3V Pin:50 mA

- DC Current per I/O Pin: $40 \mathrm{~mA}$

- Clock Speed: $16 \mathrm{MHz}$

- EEPROM: $1 \mathrm{~KB}$

- $\quad$ SRAM:2 KB

- Flash Memory: $32 \mathrm{~KB}$ of which $0.5 \mathrm{~KB}$ used by the boot loader

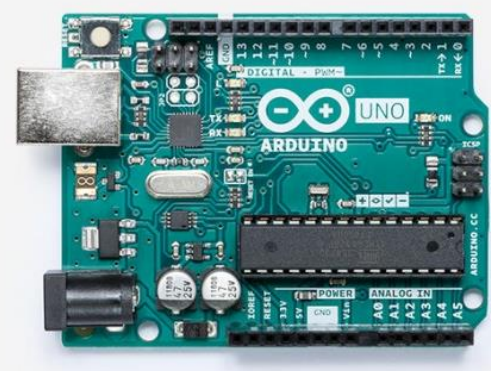

Fig. 3. Arduino UNO board.

\section{B. SIM900 GSM Shield}

SIM900 GSM/GPRS shield is a GSM modem specifically designed for the Arduino UNO, which can be integrated into a great number of IoT projects. This shield can be used to accomplish almost anything a normal cell phone can; SMS text messages, make or receive phone calls, connecting to the internet through GPRS, TCP/IP, and more! To top it off, the shield supports quad-band GSM/GPRS network, meaning it works pretty much anywhere in the world [10]. The SIM900 board is shown in figure 4 .

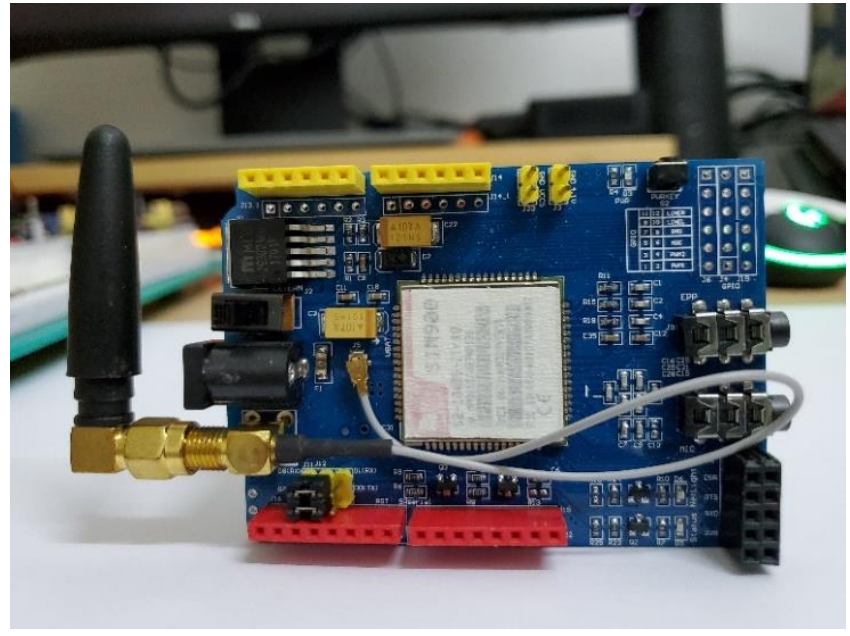

Fig. 4. SIM900 GSM/GPRS shield.

\section{Servo Motor}

A servo motor is a rotary actuator that allows for precise control of the angular position. It consists of a motor coupled to a sensor for position feedback. It also requires a servo drive to complete the system. The drive uses the feedback sensor to precisely control the rotary position of the motor. This is called a closed-loop operation. By running the system closedloop, servo motors provide a high-performance alternative to stepper [11].

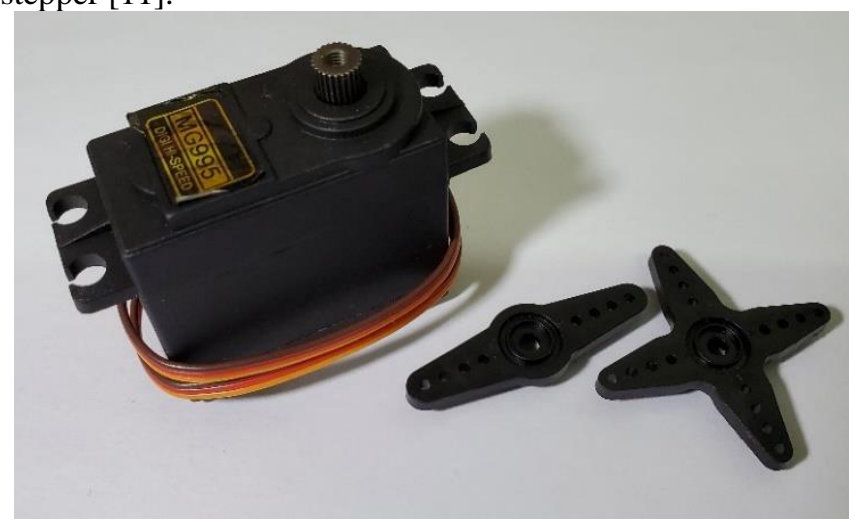

Figure 5. Servo motor.

The servo motor is shown in figure 5. The lock can be locked and unlocked by the servo motor. To unlock the lock switches the servo motor to 0 degrees and to lock the lock switches the servo to 90 degrees. The lock design is shown in figure 6 . 

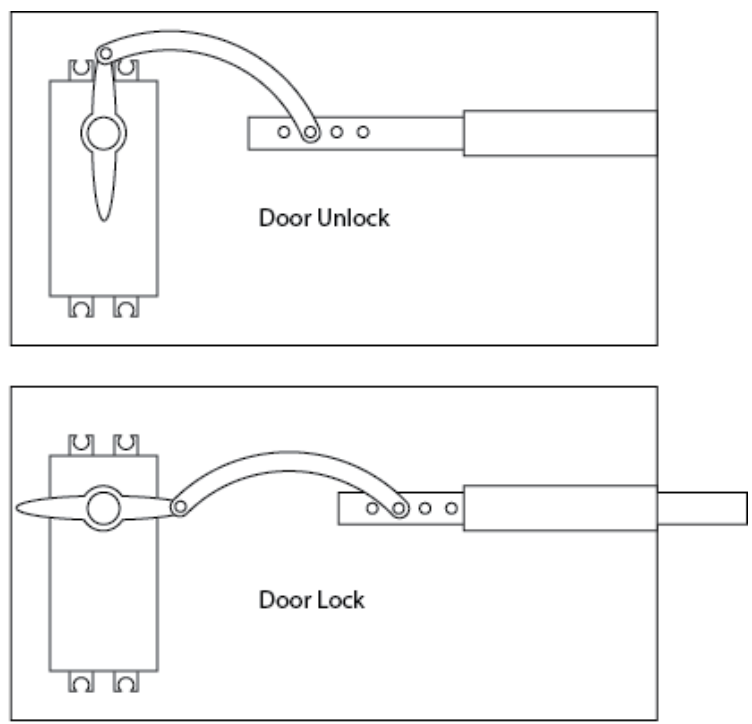

Figure. 6. The lock that use servo motor to lock and unlock.

\section{Relay and Lamp}

Relays, as shown in figure 7, are switches that open and close circuits electromechanically or electronically. Relays control one electrical circuit by opening and closing contacts in another circuit. As relay diagrams shown in figure 8, when a relay contact is normally open (NO), there is an open contact when the relay is not energized. When a relay contact is Normally Closed (NC), there is a closed contact when the relay is not energized. In either case, applying an electrical current to the contacts will change their state.

The lamp can be switch on and off by break one of the wires and connect the two broken ends to the relay. One end goes to $\mathrm{NC}$ or $\mathrm{NO}$ point and the other goes to the common (COM) point, as shown in figure 8 .

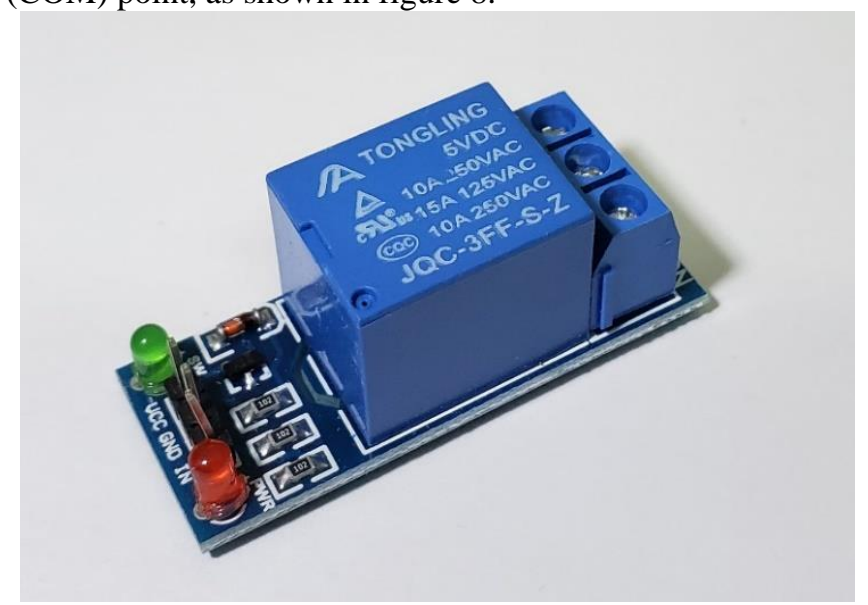

Figure. 7. Relay board dc 5v.

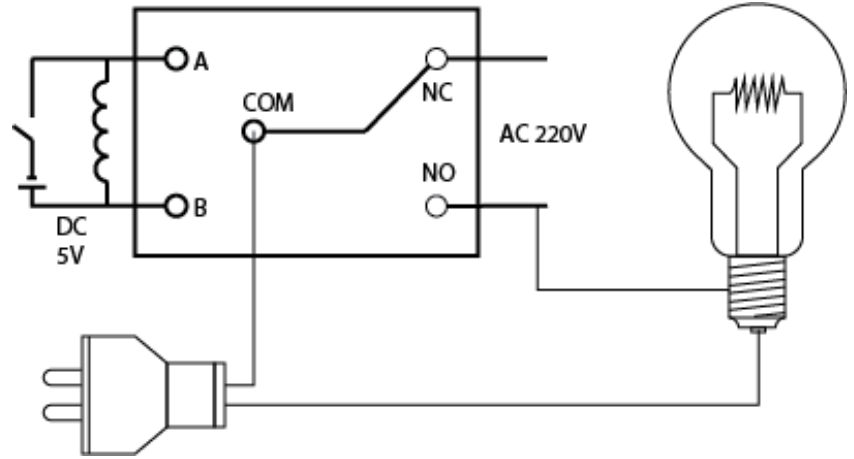

Fig. 8. Relay dc 5v diagram and connect lamp to relay.

\section{E. Door Sensor}

This project use the FengHao MC-18, it is a sensor shown in figure-9. It is a simple electric flow that used a magnetic to open and close the sensor. The electric circuit is closed when the door is shut.

As long as the door is closed, electricity can flow from one end of the circuit to the other. But if somebody opens the door, the circuit is opened, and electricity can't flow. To understand more about this sensor see in figure 10. When connecting this sensor to the Arduino board, it will send the value 0 when the door closed and 1 when the door open to the Arduino.

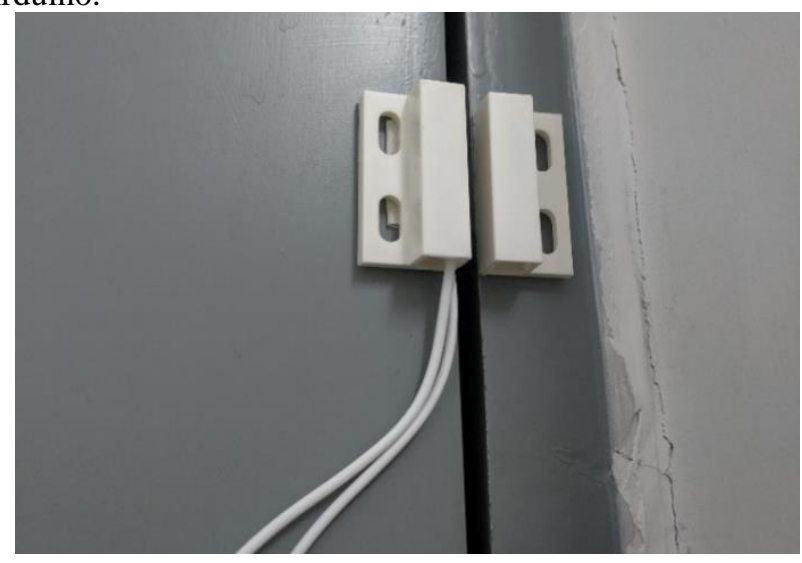

Figure. 9. MC-18 door magnetic sensor.
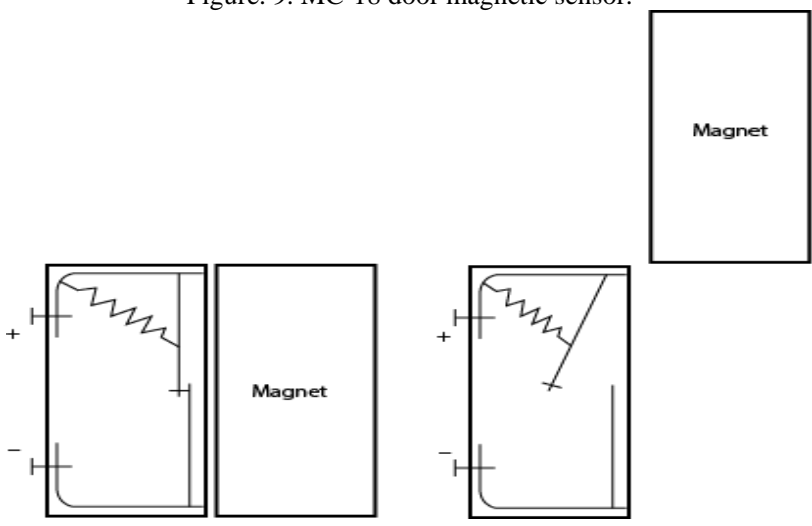

Figure. 10. Explain how the magnetic sensor work.

\section{F. Algorithm of the System}

The system has the step as below.

Step1: The system is waiting for an SMS and the door sensor.

Step2: If the system receives an SMS it will check for the phone number (the phone number already write in the code). 
If the phone number is matched to the owner's phone number, then go to the next step. But if not match do not do anything and go back to the $1^{\text {st }}$ step.

Step3: When the phone is matched read the text.

Step4: If the text is ON mean switch the lamp on.

Step5: If the text is OFF mean switch the lamp off

Step6: If the text is UNLOCK means to unlock the door and switch the lamp on.

Step7: If the text is LOCK means to lock the door and switch the lamp off
Step8: If the text is STATE mean the Owner request for the state of the door and the system will send an SMS back to the owner.

Step9: From the $1^{\text {st }}$ step, the system is also waiting for the door sensor. If the door sensor is open but the lock or the door is still locked. It means someone open the door without permission or has broken the lock. The system will send an alert SMS to the owner. The flow chart in figure 11. will show all the processes of the system.

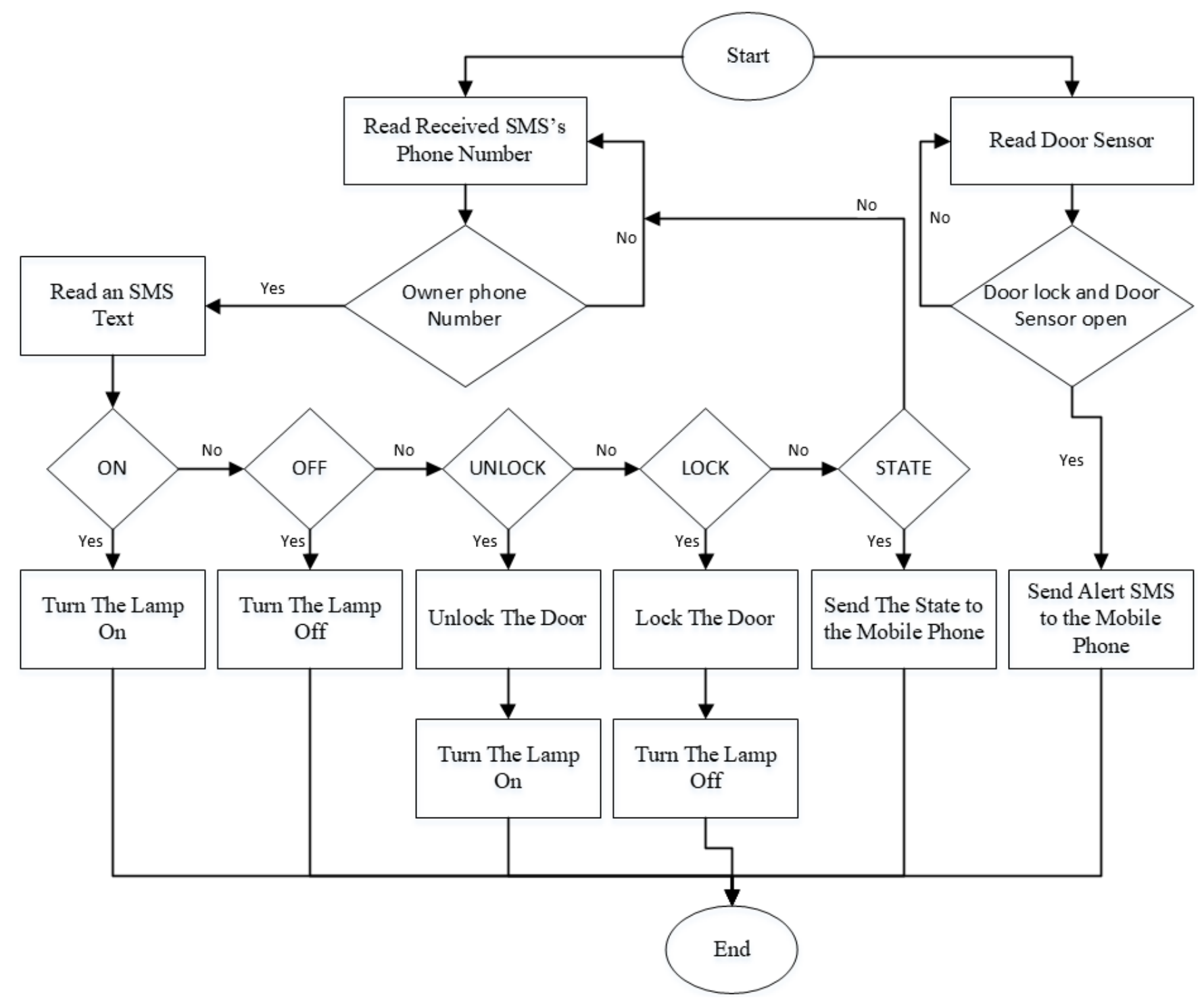

Figure 11. Flow Chart for the Smart Door Monitoring and Locking System.

\section{RESULTS AND DISCUSSION}

The Smart Door Monitoring and Locking System project has been successfully developed and implemented in the laboratory. The test system used the simulate door for the

implementation as shown in figure 12. The results are good. The system mainly consists of 4 parts. Part 1 the lock, part 2 is the lamp, part 3 is the door sensor and part 4 is the state.

Part 1 the Lock: The lock is used to lock and unlock the door by sending an SMS. When sending the text "LOCK" to the system's phone number the lock starts to lock and when send the text "UNLOCK" the lock starts to unlock. After send the SMS from the mobile phone it used about 3 seconds to success. When trying to use other phones to send an SMS to the system, it doesn't reopen any requests, after test for many time the results shown that its working as intended.

In this simulate the lock can only be locked and unlocked by an SMS, in the future should have a better design for a lock which can be unlocked and locked by using both a lock key and an SMS. 
Part 2 the Lamp: The lamp is used to provide more function for the user. When the lock is unlocked the lamp will switch on and when the lock is locked the lamp will switch off. In the test is sending an SMS text "UNLOCK" to the system to unlock the lock and after the lock unlocks the Lamp is switched on. Send an SMS text "LOCK" to the system to lock the lock after the lock locks the lamp is switched off.

The lamp also can be switched on and off without the lock's evens. Test to send the SMS text "ON" to the system then then lamp is switched on and send the SMS text "OFF" to the system then the lamp is switched off.

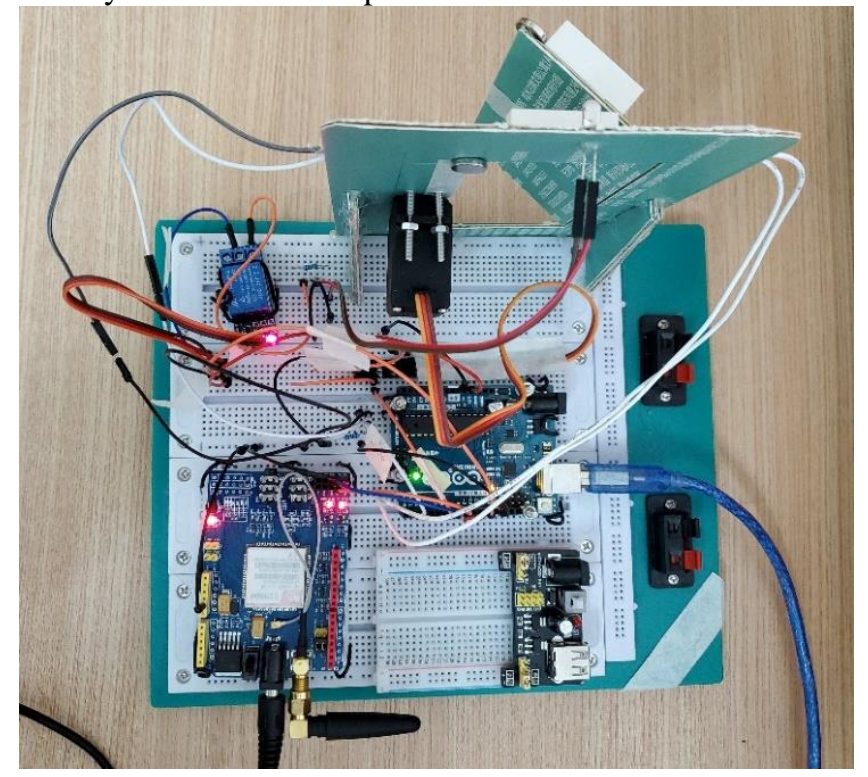

Figure 12. The complete simulate System of Smart Door Monitoring and Locking System.

The lamp part can install every kind of lamp such as: lamp with DC 5v, DC 12v, AC 220v, etc. because the relay can be use with many kinds of electric.

Part 3 the Door Sensor: The door sensor is used to detect the door that open or close. This will work with the door state if the door is lock and the sensor is open. It will send the alert massage to the owner. Because it means it will send the alert massage to the owner. Because it means someone breaks the lock and goes into the house.

In the test, when the system is in the state that the door is closed or door sensor is closed and the lock is locked, we test to open the door without unlock it. When the door is opened the mobile phone received an SMS "Door open without unlock" as shown in figure 13.

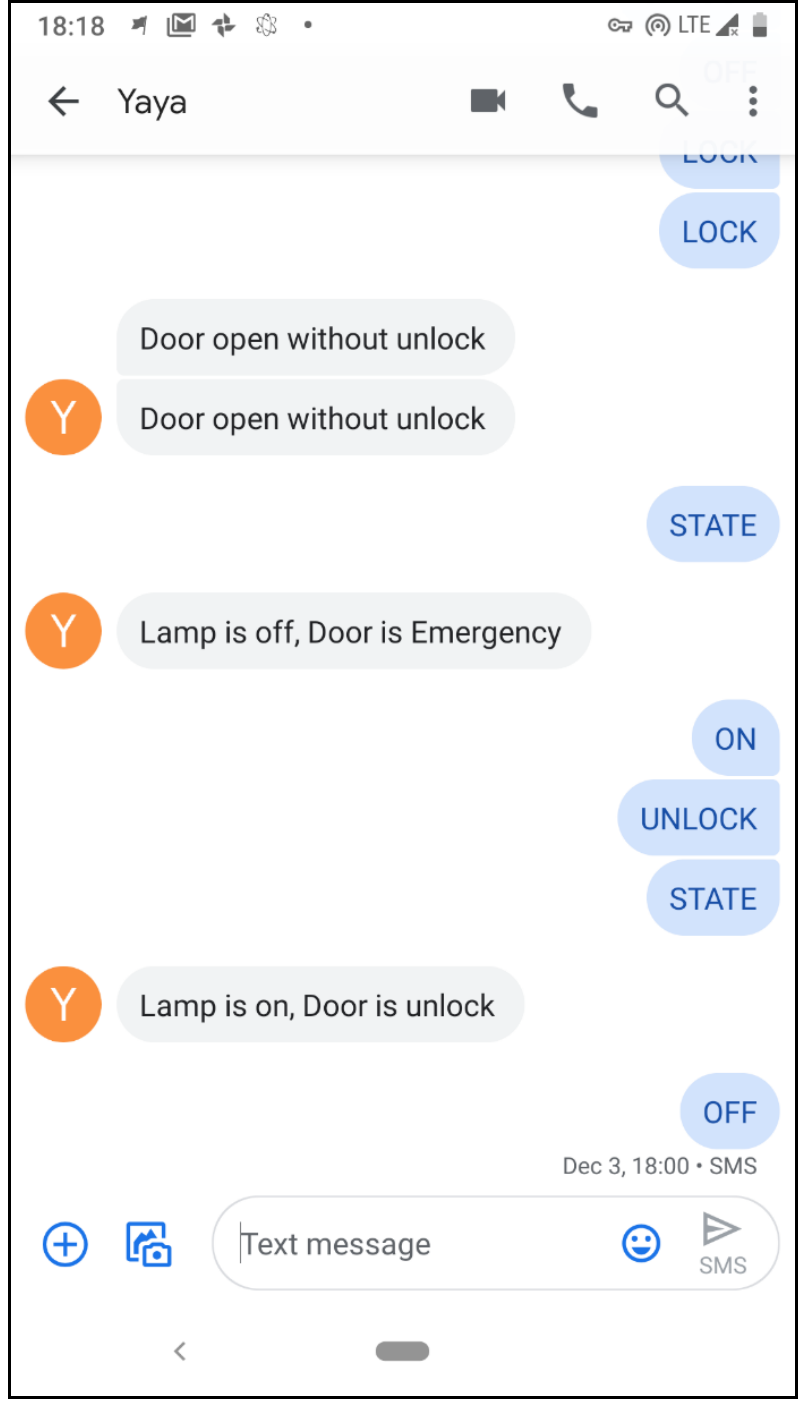

Figure. 13. Mobile phone SMS sent and receive massage.

Part 4 the State: The door open and close, the lamp switch on and off, the lock locks and unlocks and the emergency situation. Every even of the system will be saved to the state in the memory. When the owner requests it, it will send the state's status to the owner by an SMS.

In the test. We type a text "STATE" sent to the system and then after 3 second we receive an SMS "Lamp is on, Door is Unlock". This mean the door is unlock and the lamp is still lighting. But if in the Emergency situation we type a text "STATE" sent to the system. We will receive an SMS "Lam is off, door is Emergency". This mean someone break the door or the lock.

\section{CONCLUSION}

The developed system has been tested and implemented by sending an SMS for unlock the door, look the door, switch on the lamp, switch off the lamp, test for door sensor and request for the state from the system. The systems working is good. The features are like the advanced security system and low cost and standalone system. Whilst the system is a prototype the circuit will be developed on PCB using an AVR device for the microcontroller and replacing the shield with a GSM module on the PCB. An Arduino UNO and GSM Shield 
would not be used for a production model because the unit costs of using these components would make a product too costly. Therefore, redesigning the system onto PCB using components will reduce the cost of the system to enable volume production. Future work is planned to develop more features, complete systems that ready to install in real-life and can be able to setting or custom.

\section{REFERENCES}

[1] Mohammed Amenulleh " Microcontroller based programmable digital door lock security systems by using key pad GSM/CDMA Technology", IOSR Journal of electrical and Electronics Engineering (IOSR-JEEE),volume 4 ,issue 6(Mar.-Apr .2013).

[2] Murthy, B. Rama, O. Jagadish, K. Tanveer Alam, V. Mahammad Dada, and K. Priyanka Gandhi. "Development of GSM Based Advanced Alert Home Locker Safety Security System Using Arduino UNO." (2018).

[3] Sumalatha, Ch, A. Viyayamanasa, K. Ramasrujana, I. Meghamala, and K. Lakshmi Prasanna. "Bank Locker Security System Using RFID and GSM Technology." International Journal for Research in Applied Science \& Engineering Technology 4, no. 4 (2016).

[4] R.Srinivasan, T.Mettilda, D.Surendran, K.Gobinath, P.Sathishkumar, 'ADVANCED LOCKER SECURITY SYSTEM', International Journal of Advance Research In Science And Engineering,IJARSE, Vol. No.4, Special Issue (01), March 2015.Dasd.
[5] Abhishek S. Parab,Amol Joglekar, 'Implementation of Home Security System using GSM module and Microcontroller', Abhishek S. Parab et al, / (IJCSIT) International Journal of Computer Science and Information Technologies, Vol. 6 (3) , 2015, 2950-2953.

[6] Crystalynne D. Cortez, Jaswinder S. Badwal, Jocelyn R. Hipolito, Ditche Jane C. Astillero, Melvie S. Dela Cruz, and Jaira C. Inalao, 'Development of Microcontroller-Based Biometric Locker System with Short Message Service', Lecture Notes on Software Engineering, Vol. 4, No. 2, May 2016

[7] Wadhwani, Siddharth, Uday Singh, Prakarsh Singh, and Shraddha Dwivedi. "Smart home automation and security system using Arduino and IOT." Int. Res. J. Eng. Technol 5, no. 02 (2018): 1357-1359.

[8] Nasution, Tigor Hamonangan, Muhammad Anggia Muchtar, Ikhsan Siregar, Ulfi Andayani, Esra Christian, and Emerson Pascawira Sinulingga. "Electrical appliances control prototype by using GSM module and Arduino." In 2017 4th International Conference on Industrial Engineering and Applications (ICIEA), pp. 355-358. IEEE, 2017.

[9] Arduino, Store Arduino. "Arduino." Arduino LLC (2015).

[10] Zaghloul, Mohamed Saad. "GSM-GPRS Arduino Shield (GS-001) with SIM 900 chip module in wireless data transmission system for data acquisition and control of power induction furnace." International Journal of Scientific \& Engineering Research 5, no. 4 (2014): 776.

[11] Ohishi, Kiyoshi, Masato Nakao, Kouhei Ohnishi, and Kunio Miyachi. "Microprocessor-controlled DC motor for load-insensitive position servo system." IEEE transactions on industrial electronics 1 (1987) 44-49. 